\title{
Low Preoperative Albumin-to-Globulin Ratio Is a Marker of Poor Prognosis in Patients With Esophageal Cancer
}

\author{
YOSUKE ATSUMI ${ }^{1}$, SHINNOSUKE KAWAHARA ${ }^{1}$, SHO KAKUTA ${ }^{1}$, ATSUSHI ONODERA ${ }^{1}$, \\ KENTARO HARA $^{1}$, KEISUKE KAZAMA ${ }^{1}$, MASAKATSU NUMATA ${ }^{1}$, TORU AOYAMA ${ }^{1}$, AYAKO TAMAGAWA ${ }^{1}$, \\ HIROSHI TAMAGAWA ${ }^{1}$, TAKASHI OSHIMA ${ }^{2}$, NORIO YUKAWA ${ }^{1}$ and YASUSHI RINO ${ }^{1}$ \\ ${ }^{1}$ Department of Surgery, Yokohama City University, Yokohama, Japan; \\ ${ }^{2}$ Department of Gastrointestinal Surgery, Kanagawa Cancer Center, Yokohama, Japan
}

\begin{abstract}
Aim: Recent studies have reported that the albuminto-globulin ratio (AGR) may be a useful inflammatorynutritional biomarker to predict postoperative complications and poor prognosis in various types of patients with cancer. However, its prognostic value in patients with esophageal cancer is still unclear. We aimed to examine the utility of the AGR for predicting the short-and long-term outcomes in patients with esophageal cancer who underwent curative resection. Patients and Methods: This was a retrospective cohort analysis reviewing the medical records of consecutive patients who underwent esophagectomy for clinical stage I to III esophageal cancer at Yokohama City University. A total of 105 patients were identified between 2005 and 2018. The overall survival (OS), recurrencefree survival (RFS), and postoperative complication rates were compared between patients with high AGR (>1.48) and those with low AGR ( $\leq 1.48)$ group. Results: A total of 57 and 48 patients were classified into the high and low AGR groups, respectively. There was no significant difference between the two groups in the rate of overall postoperative complications of more than Clavien-Dindo grade 3 (50.9\% vs. $54.2 \%, p=0.85)$. The long-term findings showed that 5-year OS and RFS rates were significantly better for the group with a high AGR $(67.2 \% \mathrm{vs}$. $33.8 \%, p<0.001$ and $51.6 \%$ vs. $28.5 \%, p=0.003$, respectively). Conclusion: This study suggests that a low preoperative AGR is a risk factor for poor RFS and OS in patients who are planning to undergo curative surgery for esophageal cancer. AGR may be a useful biomarker for establishing treatment strategies to improve patients' survival.
\end{abstract}

This article is freely accessible online.

Correspondence to: Yosuke Atsumi, Department of Surgery, Yokohama City University, 3-9 Fukuura, Kanazawa-ku, Yokohama 236

Key Words: Esophageal cancer, albumin to globulin ratio, risk factor, operative duration.
Esophageal cancer is the seventh most common type of cancer and the sixth most common cause of cancer death worldwide (1). The standard treatment for clinical stage II and III thoracic esophageal cancer in Japan is preoperative chemotherapy with cisplatin and fluorouracil, followed by surgery (2). With advancements in surgical technique and adjuvant treatment, the prognostic outcome of esophageal cancer has improved but patients often develop tumor recurrence. The prognosis of patients with clinical stage II or III esophageal cancer after neoadjuvant chemotherapy and curative resection remains poor, with 5-year progression-free survival and overall survival (OS) rates of $44 \%$ and $55 \%$, respectively (3). Therefore, it is important to identify reliable biomarkers that predict patients with high recurrence risk and establish more effective therapeutic strategies.

Malnutrition and systemic chronic inflammation play an important role in carcinogenesis and tumor progression and have a poor prognostic effect in various types of cancer (4, 5). Albumin and globulin are two major proteins found in human serum which reflect an individual's nutritional status, and are correlated with the systemic inflammatory response (5). Recently, the albumin to globulin ratio (AGR) was identified as a novel prognostic biomarker and reported in various types of cancer (6-9). However, the prognostic value of the AGR in patients with esophageal cancer is still unclear.

The present study aimed to examine the utility of the AGR for predicting the OS and recurrence-free survival (RFS) in patients with esophageal cancer who underwent curative resection.

\section{Patients and Methods}

Patient data. Patients were selected from the medical records of consecutive patients who underwent esophagectomy for esophageal cancer at Yokohama City University from January 2005 to September 2018. The patients met the following inclusion criteria: (i) Histologically proven primary esophageal squamous cell carcinoma or adenocarcinoma, (ii) clinical stage I to III (excluding Tiv) disease as evaluated using the seventh edition of the tumor-node-metastasis 
classification established by the Union for International Cancer Control (10), and (iii) complete (R0) resection of esophageal cancer with radical lymph node dissection. Patients who had undergone R2 or R1 resection were excluded from the study.

Surgical procedure. Our standard procedures comprised open subtotal esophagectomy via right thoracotomy or video-assisted surgery, reconstruction with a gastric tube through the posterior mediastinal route or retrosternal route, and cervical or intrathoracic anastomosis. In principle, two-field lymph node dissection was indicated when tumors are located at the middle thoracic to lower thoracic esophagus, whereas three-field dissection was applied for upper thoracic tumors. A feeding tube was routinely placed at the duodenum or jejunum.

Perioperative care. All of the patients received the same perioperative management. Antibiotics were administered $30 \mathrm{~min}$ before surgical incision and every 3 hours during surgery and at postoperative day (POD) 2. The patients remained on ventilation overnight. Ambulation and enteral nutrition were started on POD 1. Oral intake was initiated on POD 5, beginning with water and gelatinous foods. The patients began to eat solid food on POD 10, starting with rice gruel and soft food and progressing in three steps to regular food intake.

Albumin to globulin ratio. The AGR was calculated based on the following equation: albumin/globulin (total proteins - albumin), evaluating the preoperative blood sample. An AGR of 1.48 was considered the optimum cutoff value by the receiver operating characteristic (ROC) curve analysis for OS [area under the curve $=0.64,95 \%$ confidence interval $(\mathrm{CI})=0.53-0.75$; Figure 1$]$ and maximizing Youden's index (sensitivity+specificity-1). This cutoff value had a sensitivity of $63.3 \%$ and a specificity of $67.9 \%$.

Follow-up. All patients underwent 3-monthly postoperative followup, and their survival status, disease progression, and time of death data were recorded for at least 5 years if possible. Serum tumor marker levels (carcinoembryonic antigen and carbohydrate antigen 19-9) were measured at least every 3 months, and computed tomography was performed at least every 6 months.

Evaluations and statistical analyses. The primary outcomes were OS and RFS, and the secondary outcome was the postoperative complication rate. The RFS and OS were defined as the period between surgery and recurrence or death, respectively, whichever came first. Postoperative surgical complications of grade 3-5 according to the Clavien-Dindo classification (11) were retrospectively determined from the patient's records. Univariate and multivariate analyses were performed to evaluate the prognostic value of AGR. Comparisons between patients with high AGR $(>1.48)$ and low AGR $(\leq 1.48)$ were analyzed using the chi-squared test or Fisher's exact test. The OS and RFS curves were plotted according to the Kaplan-Meier method, and a log-rank test was performed to identify statistical differences between the two groups. Independent prognostic factors were identified by a Cox proportional hazards regression model. Values of $p<0.05$ were considered statistically significant. All statistical analyses were performed using EZR (Saitama Medical Center, Jichi Medical University, Saitama, Japan), which is a graphic user interface for R (The R Foundation for Statistical Computing, Vienna, Australia) designed to add statistical functions frequently used in biostatistics (12)

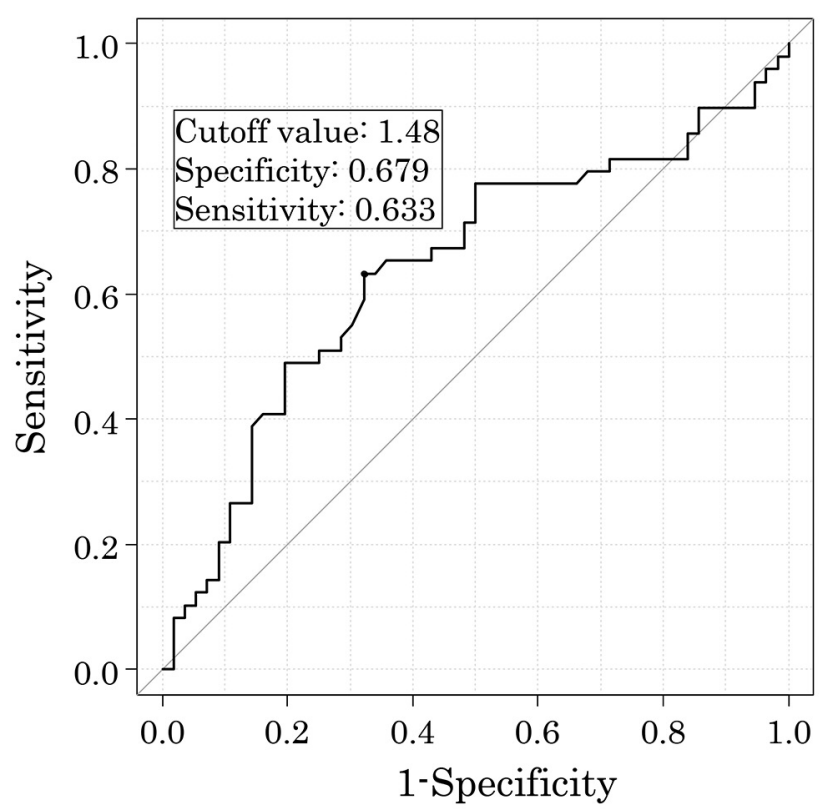

Figure 1. Receiver operating characteristic curve analysis of the albumin-to-globulin ratio in patients who underwent potentially curative surgery for esophageal cancer. Area under the curve $=0.64,95 \%$ confidence interval=0.53-0.75. An albumin-to-globulin ratio of 1.48 was considered the optimum cutoff value by maximizing Youden's index (sensitivity + specificity -1$)$.

Ethics. All study protocols were approved by the Yokohama City University Institutional Review Board (IRB number: B191100037).

\section{Results}

Patients. One hundred and five patients (male, $\mathrm{n}=90$; female, $\mathrm{n}=15$ ) were evaluated in the present study. The patient ages ranged from 40 to 82 years (median $=68$ years). The preoperative AGR ranged from 0.29 to 2.47 (median=1.52). The median follow-up period was 80.0 months (range $=22.0$ 130.0 months). A total of 57 and 48 patients were classified into the high and low AGR groups, respectively. Table I summarizes the background characteristics of the patients in the groups with high and low AGR in the present study. There were significant differences between the two groups in age and pathological depth invasion: In the group with low AGR, the percentage of patients aged 75 years or older and patients with T3 disease was greater.

Short-term outcomes. Table II summarizes patients' shortterm outcomes. There was no significant difference in the operative time ( $589 v s .597 \mathrm{~min}, p=0.50$ ) and the amount of blood loss ( $540 v s .552 .5 \mathrm{ml}, p=0.60$ ) between the high and low AGR groups. Moreover, there was no significant difference in the rate of overall postoperative complications 
Table I. Comparison between the preoperative albumin-to-globulin ratio (AGR) and clinicopathological factors in patients who underwent curative surgery for esophageal cancer.

\begin{tabular}{|c|c|c|c|c|c|}
\hline \multirow[b]{2}{*}{ Factor } & \multirow[b]{2}{*}{ Subgroup } & \multirow[b]{2}{*}{ Overall, n (\%) } & \multicolumn{2}{|c|}{ AGR, n (\%) } & \multirow[b]{2}{*}{$p$-Value } \\
\hline & & & High $(n=57)$ & Low $(n=48)$ & \\
\hline \multirow[t]{2}{*}{ Age } & $<75$ Years & $85(81.0)$ & $51(89.5)$ & $34(70.8)$ & 0.024 \\
\hline & $\geq 75$ Years & $20(19.0)$ & $6(10.5)$ & $14(29.2)$ & \\
\hline \multirow[t]{2}{*}{ Gender } & Female & $15(14.3)$ & $8(14.0)$ & $7(14.6)$ & $>0.99$ \\
\hline & Male & $90(85.7)$ & $49(86.0)$ & $41(85.4)$ & \\
\hline \multirow[t]{3}{*}{ Site of tumor } & Upper thoracic & $25(23.8)$ & $13(22.8)$ & $12(25.0)$ & $>0.99$ \\
\hline & Middle thoracic & $51(48.6)$ & $28(49.1)$ & $23(47.9)$ & \\
\hline & Lower thoracic & $29(27.6)$ & $16(28.1)$ & $13(27.1)$ & \\
\hline \multirow[t]{2}{*}{ Pathological depth invasion } & $\mathrm{T} 1-2$ & $59(56.2)$ & 38 (66.7) & $21(43.8)$ & 0.029 \\
\hline & T3 & $46(43.8)$ & $19(33.3)$ & $27(56.2)$ & \\
\hline \multirow[t]{2}{*}{ Pathological lymph node status } & Negative & $54(51.4)$ & $30(52.6)$ & $24(50.0)$ & 0.85 \\
\hline & Positive & $51(48.6)$ & $27(47.4)$ & $24(50.0)$ & \\
\hline \multirow[t]{2}{*}{ Smoking habit } & No & $10(9.5)$ & $8(14.0)$ & $2(4.2)$ & 0.11 \\
\hline & Yes & $95(90.5)$ & $49(86.0)$ & $46(95.8)$ & \\
\hline \multirow[t]{2}{*}{ Alcohol habit } & No & $13(12.4)$ & $8(14.0)$ & $5(10.4)$ & 0.77 \\
\hline & Yes & $92(87.6)$ & $49(86.0)$ & 43 (89.6) & \\
\hline \multirow[t]{2}{*}{ Operation approach } & Thoracotomy & $27(25.7)$ & $16(28.1)$ & $11(22.9)$ & 0.66 \\
\hline & Laparoscopic & $78(74.3)$ & $41(71.9)$ & $37(77.1)$ & \\
\hline \multirow[t]{2}{*}{ Lymph node dissection } & Two-field & $57(55.3)$ & $33(57.9)$ & $24(52.2)$ & 0.69 \\
\hline & Three-field & $46(44.7)$ & $24(42.1)$ & $22(47.8)$ & \\
\hline \multirow[t]{2}{*}{ Neoadjuvant chemotherapy } & No & $50(47.6)$ & $27(47.4)$ & $23(47.9)$ & $>0.99$ \\
\hline & Yes & $55(52.4)$ & $30(52.6)$ & $25(52.1)$ & \\
\hline
\end{tabular}

Table II. Short-term outcomes according to the preoperative albumin-to-globulin ratio (AGR) for patients who underwent curative surgery for esophageal cancer.

\begin{tabular}{|c|c|c|c|c|}
\hline \multirow[b]{2}{*}{ Factor } & \multirow[b]{2}{*}{ Overall } & \multicolumn{2}{|c|}{ AGR, n (\%) } & \multirow[b]{2}{*}{$p$-Value } \\
\hline & & High $(n=57)$ & Low $(n=48)$ & \\
\hline Median operative time, min (range) & $592(259-911)$ & $589(332-877)$ & $597(259-911)$ & 0.50 \\
\hline Median blood loss, $\mathrm{ml}$ (range) & $542(70-3,000)$ & $540(70-3,000)$ & $552.5(100-2,992)$ & 0.60 \\
\hline Complications, $\mathrm{n}(\%)^{*}$ & $55(52.4)$ & $29(50.9)$ & $26(54.2)$ & 0.85 \\
\hline Anastomotic leakage, n (\%) & $28(26.7)$ & $12(21.1)$ & $16(33.3)$ & 0.19 \\
\hline Pneumonia, n (\%) & $14(13.3)$ & $9(15.8)$ & $5(10.4)$ & 0.57 \\
\hline Recurrent nerve paralysis, n (\%) & $13(12.4)$ & $6(10.5)$ & $7(14.6)$ & 0.57 \\
\hline Pleural effusion, $\mathrm{n}(\%)$ & $6(5.7)$ & $4(7.0)$ & $2(4.2)$ & 0.69 \\
\hline Anastomotic stenosis, n (\%) & $4(3.8)$ & $2(3.5)$ & $2(4.2)$ & $>0.99$ \\
\hline Delayed gastric conduit emptying, n (\%) & $2(1.9)$ & $2(3.5)$ & $0(0.0)$ & 0.50 \\
\hline GI bleeding, $\mathrm{n}(\%)$ & $1(1.0)$ & $0(0.0)$ & $1(2.1)$ & 0.46 \\
\hline Bleeding, $\mathrm{n}(\%)$ & $1(1.0)$ & $1(1.8)$ & $0(0.0)$ & $>0.99$ \\
\hline Pancreatic fistula, n (\%) & $1(1.0)$ & $1(1.8)$ & $0(0.0)$ & $>0.99$ \\
\hline Heart failure, $\mathrm{n}(\%)$ & $1(1.0)$ & $1(1.8)$ & $0(0.0)$ & $>0.99$ \\
\hline Pneumothorax & $1(1.0)$ & $1(1.8)$ & $0(0.0)$ & $>0.99$ \\
\hline Median POS, days (range) & $31(13-376)$ & $23(13-376)$ & $47(13-216)$ & 0.006 \\
\hline Mortality, n (\%) & $1(1.0)$ & $0(0.0)$ & $1(2.1)$ & 0.46 \\
\hline Due to GI bleeding & $1(1.0)$ & $0(0.0)$ & $1(2.1)$ & 0.46 \\
\hline
\end{tabular}

GI: Gastrointestinal; POS: postoperative hospital stay. ${ }^{*}$ Clavien-Dindo grade $\geq 3$.

greater than Clavien-Dindo grade 3 between the two groups (50.9\% vs. $54.2 \%, p=0.85$ ). However, the duration of postoperative stay was significantly longer for the low AGR group than that for the high AGR group (23 vs. 47 days, $p=0.006)$. The mortality rate did not differ significantly between the two groups $(0.0 \%$ vs. $2.1 \%, p=0.46)$. 
Table III. Univariate and multivariate Cox proportional hazards analysis of clinicopathological factors for overall survival in patients who underwent curative surgery for esophageal cancer.

\begin{tabular}{|c|c|c|c|c|c|c|c|c|}
\hline \multirow[b]{2}{*}{ Factor } & \multirow[b]{2}{*}{ Subgroup } & \multirow[b]{2}{*}{ No. of patients } & \multicolumn{3}{|c|}{ Univariate analysis } & \multicolumn{3}{|c|}{ Multivariate analysis } \\
\hline & & & HR & $95 \% \mathrm{CI}$ & $p$-Value & HR & $95 \% \mathrm{CI}$ & $p$-Value \\
\hline \multirow[t]{2}{*}{ Age } & $<75$ Years & 85 & 1 & & & & & \\
\hline & $\geq 75$ Years & 20 & 1.59 & $1.59-5.46$ & $<0.001$ & 2.39 & $1.25-4.55$ & 0.008 \\
\hline \multirow[t]{2}{*}{ Gender } & Female & 15 & 1 & & & & & \\
\hline & Male & 90 & 1.53 & $0.60-3.86$ & 0.37 & & & \\
\hline \multirow[t]{2}{*}{ Site of tumor } & Upper thoracic & 25 & 1 & & & & & \\
\hline & Middle-Lower & 80 & 1.1 & $0.56-2.16$ & 0.8 & & & \\
\hline \multirow[t]{2}{*}{ Pathological depth invasion } & $\mathrm{T} 1-2$ & 59 & 1 & & & & & \\
\hline & T3 & 46 & 2.84 & $1.60-5.04$ & $<0.001$ & 1.1 & $1.11-1.18$ & 0.004 \\
\hline \multirow[t]{2}{*}{ Pathological lymph node status } & Negative & 54 & 1 & & & & & \\
\hline & Positive & 51 & 2.01 & $1.13-3.57$ & 0.016 & 1.68 & $0.93-3.05$ & 0.088 \\
\hline \multirow[t]{2}{*}{ Operation approach } & Laparoscopic & 78 & 1 & & & & & \\
\hline & Thoracotomy & 27 & 1.05 & $0.56-1.99$ & 0.88 & & & \\
\hline \multirow[t]{2}{*}{ Lymph node dissection } & Two-field & 57 & 1 & & & & & \\
\hline & Three-field & 46 & 1.06 & $0.59-1.88$ & 0.85 & & & \\
\hline \multirow[t]{2}{*}{ Neoadjuvant chemotherapy } & Yes & 55 & 1 & & & & & \\
\hline & No & 50 & 1.22 & $0.70-2.14$ & 0.48 & & & \\
\hline \multirow[t]{2}{*}{ Preoperative AGR } & $>1.48$ & 57 & 1 & & & & & \\
\hline & $\leq 1.48$ & 48 & 3.01 & $1.69-5.38$ & $<0.001$ & 2.27 & $1.24-4.17$ & 0.008 \\
\hline
\end{tabular}

AGR: Albumin-to-globulin ratio; CI: confidence intervaI; HR: hazard ratio.

Table IV. Univariate and multivariate Cox proportional hazards analysis of the relationship between clinic pathological factors and recurrencefree survival in patients who underwent curative surgery for esophageal cancer.

\begin{tabular}{|c|c|c|c|c|c|c|c|c|}
\hline \multirow[b]{2}{*}{ Factor } & \multirow[b]{2}{*}{ Subgroup } & \multirow[b]{2}{*}{ Patients, $\mathrm{n}$} & \multicolumn{3}{|c|}{ Univariate analysis } & \multicolumn{3}{|c|}{ Multivariate analysis } \\
\hline & & & HR & $95 \% \mathrm{CI}$ & $p$-Value & HR & $95 \% \mathrm{CI}$ & $p$-Value \\
\hline \multirow[t]{2}{*}{ Age } & $<75$ Years & 85 & 1 & & & 1 & & \\
\hline & $\geq 75$ Years & 20 & 2.02 & $1.12-3.65$ & 0.017 & 1.69 & $0.91-3.11$ & 0.094 \\
\hline \multirow[t]{2}{*}{ Gender } & Female & 15 & 1 & & & & & \\
\hline & Male & 90 & 1.42 & $0.65-3.14$ & 0.378 & & & \\
\hline \multirow[t]{2}{*}{ Site of tumor } & Upper thoracic & 25 & 1 & & & & & \\
\hline & Middle-Lower & 80 & 1.07 & $0.59-1.95$ & 0.83 & & & \\
\hline \multirow[t]{2}{*}{ Pathological invasion depth } & $\mathrm{T} 1-2$ & 59 & 1 & & & 1 & & \\
\hline & $\mathrm{T} 3$ & 46 & 2.8 & $1.65-4.74$ & $<0.001$ & 2.23 & $1.29-3.87$ & 0.004 \\
\hline \multirow[t]{2}{*}{ Pathological LN status } & Negative & 54 & 1 & & & 1 & & \\
\hline & Positive & 51 & 2.02 & $1.20-3.41$ & 0.007 & 1.68 & $0.98-2.91$ & 0.061 \\
\hline \multirow[t]{2}{*}{ Operative approach } & Laparoscopic & 27 & 1 & & & & & \\
\hline & Thoracotomy & 78 & 1.33 & $0.75-2.34$ & 0.327 & & & \\
\hline \multirow[t]{2}{*}{ Lymph node dissection } & Two-field & 57 & 1 & & & & & \\
\hline & Three-field & 46 & 1.04 & $0.61-1.76$ & 0.882 & & & \\
\hline \multirow[t]{2}{*}{ Neoadjuvant chemotherapy } & No & 50 & 1 & & & & & \\
\hline & Yes & 55 & 1.21 & $0.72-2.03$ & 0.479 & & & \\
\hline \multirow[t]{2}{*}{ Preoperative AGR } & $>1.48$ & 57 & 1 & & & 1 & & \\
\hline & $\leq 1.48$ & 48 & 2.17 & 1.29 & 0.003 & 1.72 & $1.00-2.96$ & 0.049 \\
\hline
\end{tabular}

AGR: Albumin-to-globulin ratio; CI: confidence intervaI; HR: hazard ratio; LN: lymph node.

Survival analyses. The 5-year OS rates after surgery were $67.2 \%$ for the high AGR group and $33.8 \%$ for the low AGR group $(p<0.001)$. The OS curves are shown in Figure 2. Univariate analyses for OS showed that the AGR was a significant prognostic factor, as were age, depth of tumor invasion, and lymph node status (Table III). The AGR, age, and depth of tumor 


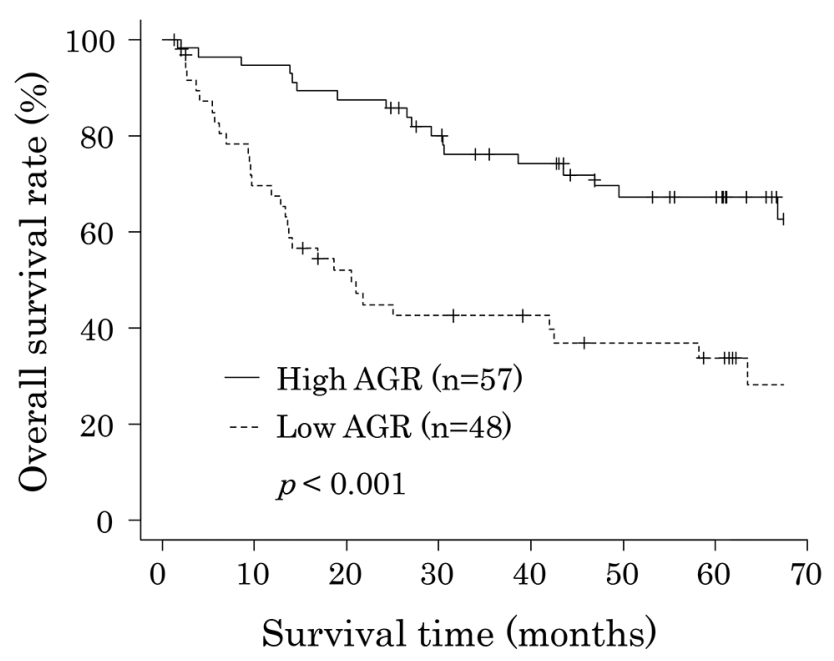

Figure 2. A comparison of the overall survival rates in the groups with high and low albumin-to-globulin ratio (AGR) after curative surgery for esophageal cancer.

invasion were selected for the final model to be analyzed using a multivariate analysis. The 5-year RFS rates after surgery were $51.6 \%$ for the high AGR group and $28.5 \%$ for the low AGR group, which was also a statistically significant difference $(p=0.003)$. The RFS curves are shown in Figure 3 . The univariate analysis of factors associated with RFS showed that the AGR was a significant prognostic factor, as were age, depth of tumor invasion, and lymph node status (Table IV), which were the same factors as those for OS. The multivariate analysis showed that the AGR and depth of invasion were significant prognostic factors associated with RFS.

During the study period, 23 out of the $57(40.4 \%)$ patients in the high AGR group and 25 of the 48 (52.1\%) patients in the low AGR group developed recurrence. Comparison of the distribution of the sites of recurrence showed no significant difference between the two groups (Table V). The major sites of recurrence in the high AGR group were extraregional lymph nodes, lungs, and liver in order of frequency, while those in the low AGR group were extra-regional lymph nodes, liver, and lungs.

\section{Discussion}

The present study aimed to evaluate the clinical impact of the AGR, which was calculated from preoperatively measured serum total protein, albumin, and globulin (serum total protein - albumin), in patients who underwent curative resection for esophageal cancer. We have shown that the AGR was a significant risk factor for RFS and OS in those patients. Therefore, the AGR may be a useful biomarker that can identify patients with esophageal cancer who require more effective therapeutic strategies.

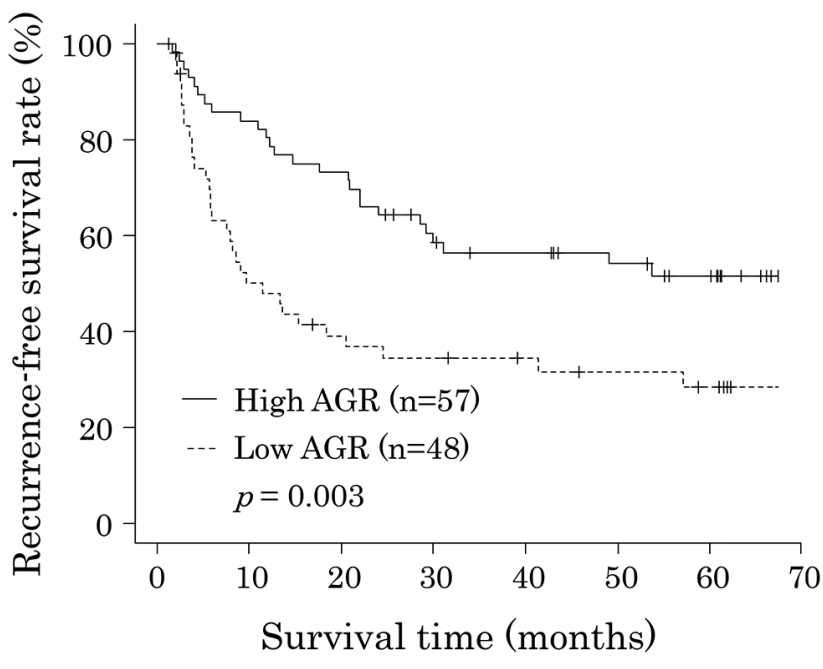

Figure 3. A comparison of the recurrence-free survival rate in the high and low albumin to globulin ratio (AGR) groups after curative surgery for esophageal cancer.

Table V. Sites of recurrence of esophageal cancer according to the preoperative albumin-to-globulin ratio $(A G R)(n=48)$.

\begin{tabular}{lcccr}
\hline & & \multicolumn{3}{c}{ AGR, n (\%) } \\
\cline { 3 - 4 } & & & \\
& Overall, n (\%) & High (n=23) & Low (n=25) & $p$-Value \\
\hline $\begin{array}{l}\text { Extra-regional } \\
\text { lymph node }\end{array}$ & $32(66.7)$ & $16(69.6)$ & $16(64.0)$ & 0.77 \\
Lung & $12(25.0)$ & $8(34.8)$ & $4(16.0)$ & 0.19 \\
Liver & $10(20.8)$ & $3(13.0)$ & $7(28.0)$ & 0.29 \\
Brain & $5(10.4)$ & $2(8.7)$ & $3(12.0)$ & $>0.99$ \\
Pleura & $3(6.2)$ & $0(0.0)$ & $3(12.0)$ & 0.24 \\
Bone & $3(6.2)$ & $1(4.3)$ & $2(8.0)$ & $>0.99$ \\
Local & $3(6.2)$ & $2(8.7)$ & $1(4.0)$ & 0.60 \\
Peritoneum & $1(2.1)$ & $0(0.0)$ & $1(4.0)$ & $>0.99$ \\
Adrenal gland & $1(2.1)$ & $0(0.0)$ & $1(4.0)$ & $>0.99$ \\
Spleen & $1(2.1)$ & $1(4.3)$ & $0(0.0)$ & 0.48 \\
\hline
\end{tabular}

To the best of our knowledge, there are only two previous studies that investigated the prognostic significance of AGR in patients with esophageal cancer. Oki et al. assessed the prognostic impact of AGR in 112 patients with esophageal cancer who underwent surgery (13). Multivariate analyses demonstrated that lower AGR was an independent predictive factor for poor OS [hazard ratio $(\mathrm{HR})=0.47,95 \% \mathrm{CI}=0.24$ $0.92, p=0.028]$ and DFS $(\mathrm{HR}=0.37,95 \% \mathrm{CI}=0.16-0.85$; $p=0.02$ ), and our findings were consistent with those of their study. In contrast, according to Zhang et al.'s retrospective study including 458 patients with esophageal squamous cell cancer who underwent radical esophagectomy, the preoperative AGR was not an independent prognostic 
indicator (14). However, they did show that having a high albumin level $(\geq 4.56 \mathrm{mg} / \mathrm{dl})$ and low globulin level $(<2.69$ $\mathrm{mg} / \mathrm{dl})$ was significantly associated with favorable OS $(\mathrm{HR}=0.630,95 \% \mathrm{CI}=0.418-0.952 ; p=0.028)$ in multivariate models. According to Zhang et al., possible reasons why the preoperative AGR was not an independent prognostic indicator for esophageal squamous cell cancer remained unclear. However, previous studies yielded conflicting results. The present and Oki et al.'s studies were conducted in Japan and included patients who were treated with surgery and neoadjuvant chemotherapy because they are standard therapies for clinical stage II and III thoracic esophageal cancer in Japan (3). In contrast, Zhang et al.'s study, which was conducted in China and excluded patients who received preoperative chemotherapy. AGR might be an independent prognostic indicator only for patients with esophageal cancer receiving neoadjuvant chemotherapy.

An association between the AGR and survival of patients with esophageal cancer may be biologically plausible and requires further elucidation. Serum albumin is an indicator of poor nutritional status. Nutritional disorders have been shown to occur not only in patients with advanced cancer but also in patients with early-stage cancer, and they have been identified as independent prognostic factors (15-19). It was reported that nutritional disorders increase the risk of infection in the perioperative period and increase adverse events during systemic chemotherapy, which negatively affected the efficacy and continuity of treatment (20). Moreover, serum globulin has been confirmed to be involved in the inflammatory process $(5,21)$. Previous studies have shown that an inflammatory response in the tumor microenvironment can contribute to tumor progression, distant metastasis, antitumor immunity reduction, and oncological treatment weakening, thus leading to poor prognosis (21-26).

This study has some limitations. Firstly, a consensus regarding the optimal cutoff point for the AGR is still unknown. In the present study, we set the cutoff value of AGR at 1.48 according to the ROC and 5-year OS rates. Similarly, Oki et al. set 1.41 as their cutoff value according to the ROC curve analysis with Youden's index (13). Zhang et al. set 1.30 as their cutoff value of AGR according to the method established by Jan Budczies et al. (14, 27). The optimal method for evaluating the AGR and the ideal cutoff value need to be clarified before this parameter can be implemented in daily clinical practice. Secondly, selection bias might have been present due to the retrospective, nonrandomized design of this study. Thirdly, the present study comprised a small sample size. Thus, our findings were possibly observed by chance. Further prospective investigations with larger sample sizes are required to confirm our results. However, despite these limitations, our finding was significant considering that it identifies and predicts patients with high risk of recurrence who require more effective therapeutic strategies.

\section{Conclusion}

Our study suggests that the preoperative AGR is a risk factor for poor RFS and OS in patients who are planning to undergo curative surgery for esophageal cancer. AGR may be a useful biomarker for establishing treatment strategies to improve patients' survival.

\section{Conflicts of Interest}

The Authors declare that they have no conflicts of interest in regard to this study.

\section{Authors' Contributions}

All Authors contributed to the study conception and design. Data collection was performed by Yosuke Atsumi, Shinnosuke Kawahara, Sho Kakuta, Atsushi Onodera, Kentaro Hara, Keisuke Kazama, Masakatsu Numata, Toru Aoyama, Ayako Tamagawa, Hiroshi Tamagawa, Norio Yukawa, and Yasushi Rino. Statistical analysis was performed by Yosuke Atsumi. The first draft of the article was written by Yosuke Atsumi, and all Authors commented on previous versions of the article. All Authors read and approved the final article.

\section{References}

1 Bray F, Ferlay J, Soerjomataram I, Siegel RL, Torre LA and Jemal A: Global cancer statistics 2018: GLOBOCAN estimates of incidence and mortality worldwide for 36 cancers in 185 countries. CA Cancer J Clin 68(6): 394-424, 2018. PMID: 30207593. DOI: $10.3322 / \mathrm{caac} .21492$

2 Kitagawa Y, Uno T, Oyama T, Kato K, Kato H, Kawakubo H, Kawamura O, Kusano M, Kuwano H, Takeuchi H, Toh Y, Doki Y, Naomoto Y, Nemoto K, Booka E, Matsubara H, Miyazaki T, Muto M, Yanagisawa A and Yoshida M: Esophageal cancer practice guidelines 2017 edited by the Japan esophageal society: part 2. Esophagus 16(1): 25-43, 2019. PMID: 30171414. DOI: 10.1007/s10388-018-0642-8

3 Ando N, Kato H, Igaki H, Shinoda M, Ozawa S, Shimizu H, Nakamura T, Yabusaki H, Aoyama N, Kurita A, Ikeda K, Kanda T, Tsujinaka T, Nakamura $\mathrm{K}$ and Fukuda $\mathrm{H}$ : A randomized trial comparing postoperative adjuvant chemotherapy with cisplatin and 5-fluorouracil versus preoperative chemotherapy for localized advanced squamous cell carcinoma of the thoracic esophagus (JCOG9907). Ann Surg Oncol 19(1): 68-74, 2012. PMID: 21879261. DOI: 10.1245/s10434-011-2049-9

4 Bromberg J and Wang TC: Inflammation and cancer: IL-6 and STAT3 complete the link. Cancer Cell 15(2): 79-80, 2009. PMID: 19185839. DOI: 10.1016/j.ccr.2009.01.009

5 McMillan DC, Watson WS, O'Gorman P, Preston T, Scott HR and McArdle CS: Albumin concentrations are primarily determined by the body cell mass and the systemic inflammatory response in cancer patients with weight loss. Nutr Cancer 39(2): 210-213, 2001. PMID: 11759282. DOI: 10.1207/S15327 914nc392_8

6 Azab B, Kedia S, Shah N, Vonfrolio S, Lu W, Naboush A, Mohammed F and Bloom SW: The value of the pretreatment albumin/globulin ratio in predicting the long-term survival in 
colorectal cancer. Int J Colorectal Dis 28(12): 1629-1636, 2013. PMID: 23857599. DOI: 10.1007/s00384-013-1748-Z

7 Guo HW, Yuan TZ, Chen JX and Zheng Y: Prognostic value of pretreatment albumin/globulin ratio in digestive system cancers: A meta-analysis. PLoS One 13(1): e0189839, 2018. PMID: 29300750. DOI: 10.1371/journal.pone.0189839

8 He J, Pan H, Liang W, Xiao D, Chen X, Guo M and He J: Prognostic effect of albumin-to-globulin ratio in patients with solid tumors: a systematic review and meta-analysis. J Cancer 8(19): 4002-4010, 2017. PMID: 29187875. DOI: 10.7150/ jca. 21141

9 Chen WZ, Yu ST, Xie R, Lv YX, Xu DB and Yu JC: Preoperative albumin/globulin ratio has predictive value for patients with laryngeal squamous cell carcinoma. Oncotarget 8(29): 48240-48247, 2017. PMID: 28654895. DOI: 10.18632/ oncotarget. 18443

10 Sobin LH, Gospodarowicz MK and Wittekind C: TNM classification of malignant tumours. John Wiley \& Sons, 2011.

11 Dindo D, Demartines N and Clavien PA: Classification of surgical complications: a new proposal with evaluation in a cohort of 6336 patients and results of a survey. Ann Surg 240(2): 205-213, 2004. PMID: 15273542. DOI: 10.1097/01.sla. 0000133083.54934.ae

12 Kanda Y: Investigation of the freely available easy-to-use software 'EZR' for medical statistics. Bone Marrow Transplant 48(3): 452-458, 2013. PMID: 23208313. DOI: 10.1038/bmt. 2012.244

13 Oki S, Toiyama Y, Okugawa Y, Shimura T, Okigami M, Yasuda H, Fujikawa H, Okita Y, Yoshiyama S, Hiro J, Kobayashi M, Ohi M, Araki T, Inoue Y, Mohri Y and Kusunoki M: Clinical burden of preoperative albumin-globulin ratio in esophageal cancer patients. Am J Surg 214(5): 891-898, 2017. PMID: 28460738. DOI: 10.1016/j.amjsurg.2017.04.007

14 Zhang F, Sun P, Wang ZQ, Wang de S, Wang Y, Zhang DS, Wang $\mathrm{FH}, \mathrm{Fu} \mathrm{JH}, \mathrm{Xu} \mathrm{RH}$ and $\mathrm{Li}$ YH: Low preoperative albumin-globulin score predicts favorable survival in esophageal squamous cell carcinoma. Oncotarget 7(21): 30550-30560, 2016. PMID: 27105522. DOI: 10.18632/oncotarget.8868

15 Yang Y, Gao P, Song Y, Sun J, Chen X, Zhao J, Ma B and Wang $\mathrm{Z}$ : The prognostic nutritional index is a predictive indicator of prognosis and postoperative complications in gastric cancer: A meta-analysis. Eur J Surg Oncol 42(8): 1176-1182, 2016. PMID: 27293109. DOI: 10.1016/j.ejso.2016.05.029

16 Tokunaga R, Sakamoto Y, Nakagawa S, Miyamoto Y, Yoshida $\mathrm{N}$, Oki E, Watanabe M and Baba H: Prognostic nutritional index predicts severe complications, recurrence, and poor prognosis in patients with colorectal cancer undergoing primary tumor resection. Dis Colon Rectum 58(11): 1048-1057, 2015. PMID: 26445177. DOI: 10.1097/DCR.0000000000000458

17 Mohri T, Mohri Y, Shigemori T, Takeuchi K, Itoh Y and Kato T: Impact of prognostic nutritional index on long-term outcomes in patients with breast cancer. World J Surg Oncol 14(1): 170, 2016. PMID: 27349744. DOI: 10.1186/s12957-016-0920-7
18 Haraga J, Nakamura K, Omichi C, Nishida T, Haruma T, Kusumoto T, Seki N, Masuyama H, Katayama N, Kanazawa S and Hiramatsu Y: Pretreatment prognostic nutritional index is a significant predictor of prognosis in patients with cervical cancer treated with concurrent chemoradiotherapy. Mol Clin Oncol 5(5): 567-574, 2016. PMID: 27900086. DOI: 10.3892/mco. 2016.1028

19 Sakai M, Sohda M, Miyazaki T, Yoshida T, Kumakura Y, Honjo H, Hara K, Ozawa D, Suzuki S, Tanaka N, Yokobori T and Kuwano H: Association of preoperative nutritional status with prognosis in patients with esophageal cancer undergoing salvage esophagectomy. Anticancer Res 38(2): 933-938, 2018. PMID: 29374724. DOI: 10.21873 /anticanres.12306

20 McMillan DC: The systemic inflammation-based Glasgow Prognostic Score: a decade of experience in patients with cancer. Cancer Treat Rev 39(5): 534-540, 2013. PMID: 22995477. DOI: 10.1016/j.ctrv.2012.08.003

21 Gabay C and Kushner I: Acute-phase proteins and other systemic responses to inflammation. N Engl J Med 340(6): 448-454, 1999. PMID: 9971870. DOI: 10.1056/NEJM199902113400607

22 Coussens LM and Werb Z: Inflammation and cancer. Nature 420(6917): 860-867, 2002. PMID: 12490959. DOI: 10.1038/ nature 01322

23 Colotta F, Allavena P, Sica A, Garlanda C and Mantovani A: Cancer-related inflammation, the seventh hallmark of cancer: links to genetic instability. Carcinogenesis 30(7): 1073-1081, 2009. PMID: 19468060. DOI: 10.1093/carcin/bgp127

24 Roxburgh CS and McMillan DC: Role of systemic inflammatory response in predicting survival in patients with primary operable cancer. Future Oncol 6(1): 149-163, 2010. PMID: 20021215. DOI: 10.2217 /fon.09.136

25 Sakai M, Sohda M, Saito H, Ubukata Y, Nakazawa N, Kuriyama K, Hara K, Sano A, Ogata K, Yokobori T, Shirabe K and Saeki $\mathrm{H}$ : Comparative analysis of immunoinflammatory and nutritional measures in surgically resected esophageal cancer: a singlecenter retrospective study. In Vivo 34(2): 881-887, 2020. PMID: 32111799. DOI: 10.21873/invivo.11853

26 Miyazaki T, Sakai M, Sohda M, Tanaka N, Yokobori T, Motegi Y, Nakajima M, Fukuchi M, Kato H and Kuwano H: Prognostic significance of inflammatory and nutritional parameters in patients with esophageal cancer. Anticancer Res 36(12): 65576562, 2016. PMID: 27919983. DOI: 10.21873/anticanres.11259

27 Budczies J, Klauschen F, Sinn BV, Győrffy B, Schmitt WD, Darb-Esfahani S and Denkert C: Cutoff Finder: a comprehensive and straightforward Web application enabling rapid biomarker cutoff optimization. PLoS One 7(12): e51862, 2012. PMID: 23251644. DOI: 10.1371/journal.pone.0051862

Received June 30, 2021

Revised August 18, 2021

Accepted August 26, 2021 